\title{
Development of a Customized Mobile Application in Sport Education
}

\author{
Hyeonho Yu \& Pamela H. Kulinna \\ Arizona State University
}

\section{Introduction}

Sport education (SE) aims to help students to be three kinds of sportspersons: (a) a competent sportsperson, (b) a literate sportsperson, and (c) an enthusiastic sportsperson (Siedentop et al., 2020). Experienced teachers reported that SE provided them with time for observing, giving feedback, and praising students individually (Brunton, 2003). However, pre-service teachers may have a hard time using the model because of a lack of full understanding about the curriculum as well as the large amount of time it takes to prepare for seasons (McMahon \& MacPhail, 2007). The preparation may be a burden for pre-service teachers if it is their first-time implementing SE (Deenihan \& MacPhail, 2013).

The appropriate use of technology such as mobile applications (Apps) may provide another vehicle to assist teachers with teaching the SE curricular model. For instance, the season schedules, game scores, individual/team data, and other information can be managed by the Apps. However, very few studies have addressed the integration of Apps into physical education. Therefore, the purpose of the study was to design and develop a customized App named Smart Sports for the SE curricular model and to examine the utility of the App based on physical education teacher education (PETE) students' feedback.

Keywords: mobile application, technology, sport education

\section{Article History}

Received 11 September 2020

Accepted 28 September 2020

Published 31 October 2020

Available online 31 December 2020

https://doi.org/10.47544/johsk.2020.1.1.9

Corresponding Author
Hyeonho Yu
hyeonhoyu@gmail.com
Physical Education Teacher Education Program
Mary Lou Fulton Teachers College
Arizona State University, USA

Corresponding Author

Arizona

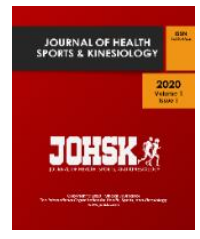

\section{Methods}

Two sport pedagogy experts (2 Caucasians; 1 male, 1 female) and eight graduate students (7 Caucasians, 1 African American; 3 males, 5 females) in a PETE program in the Southwestern USA participated in this study. Informed by the Analysis, Design, Development, Implementation, and Evaluation model (ADDIE), which is one of analysis methods for effectiveness of use of many types of instruction, the five phases: (a) analysis of curriculum, (b) design, (c) development of an App, (d) implementation of the App, and (e) evaluation of the APP, can be performed to build effective curriculum support tools (Hannum, 2005). A discussion for designing the Smart Sports App with two sport pedagogy experts was held prior to developing the App. All the necessary features for teachers were discussed in the meeting. Based upon the summary of suggestions from the experts, the customized App (Smart Sports) was developed and updated on weekly basis. Participants utilized the App in the SE class for three

\section{Journal of Health Sports \& Kinesiology | ISSN 2692-9864 | www.johsk.com}


| 2020 | Volume 1 | Issue 1 | The Journal of Health, Sports, and Kinesiology |

weeks and gave feedback through open-ended pre/post surveys.

From the first day of the study, students were asked to take the pre-survey by answering the questions: (a) their experiences teaching the SE curriculum, (b) their paperwork before SE lessons, (c) familiarity with mobile Apps, and (d) expectations of using the SE App. With five rounds of revisions and updates, the Smart Sports App had been implemented in the SE classes. The post-survey was conducted after a three-week period of using the App and the survey questions included: (a) overall thoughts about the SE App, (b) interesting moments while using the App, (c) features in the App (advantages/challenges), and (d) willingness to use the App in their classes.

\section{Results}

According to the results of the pre-survey, all but one of the participants had previous experience with SE. Only two participants were familiar with using Apps in their teaching. They mentioned copies of contract forms and rules, signs, team information, expectations and guidelines, team organization, statistics sheets, team binders, and lesson plans as the paperwork teachers have to prepare before SE seasons. Three of participants were looking forward to reducing the paperwork by using the Smart Sports App and two participants wanted to learn how to incorporate the App for recording game statistics.

Three participants reported in the post-survey that, as to the interesting moment that happened while they were using the SE App, they enjoyed using the countdown timer and scoreboards. All the participants mentioned that the App would motivate student learning because they, as students, enjoyed new ways of learning with the App technology. All the respondents commented that they would like to offer the use of the App to their peers or other physical education teachers because they found the App's potential to enable teachers to teach SE during team practice and formal competitions. Three of participants commented that the App would be helpful for out of class practice or physical activity because students might want to keep track of their activity and perhaps have contests with peers. Overall comments were very positive that the App had a great deal of potential for helping keep track of season statistics, scores, fair play points, etc. and that it made using the SE curricular model less stressful for teachers and students. After the post-survey, the Smart Sports App was updated for a final (6 $\left.6^{\text {th }}\right)$ time. This final update included scoreboards being divided into different types of sports/activities (i.e., scoreboard for coach, net/court sports, striking/fielding sports, basketball, football, and track/field sports).

\section{Discussion}

Framed by ADDIE model, the effectiveness of the customized App in a formal SE course in a PETE program was evaluated in the study. In spite of the pre-service teachers' positive impression of SE in PETE, the gap of experiences between PETE training and real teaching may lead to difficulties for PETE students in starting SE seasons (McMahon \& MacPhail, 2007). The appropriate delivery of the SE in PETE with scaffolding strategies is therefore essential. Appropriate use of technology (e.g., mobile Apps) will help them deliver SE effectively. Teacher educators in PETE should provide the pre-service teachers with proactive and supportive lessons using appropriate technology along with many examples of teaching scenarios and how to handle events in the classes.

Physical education teachers should be exposed to cutting-edge technologies so that they know the possibilities of what they can do and what students can do in their educational contexts. However, it is important for teachers to select appropriate technologies due to the lack of Apps that match with physical education pedagogical models. In this study, the faculty members' suggestions for the App design and the pre-service teachers' feedback played important roles in developing the customized App that may affect their ability in teaching the model. Considering that this study was based on the investigation of one educational App after consultation with sport pedagogy faculty in a PETE program, further investigation and application in other settings are needed.

\section{Conclusion}

This study provided information regarding how to design and develop a physical education App for effective teaching. Using the customized App in the SE class of a PETE program had a positive effect on teachers' delivery of the model. Further examination of the integration of technology into other curricular models for physical education are warranted.

Journal of Health Sports \& Kinesiology | ISSN 2692-9864 | www.johsk.com 


\section{References}

Brunton J. A. (2003). Changing hierarchies of power in physical education using sport education. European Physical Education Review 9(3), 267-284.

Deenihan, J. T., \& MacPhail, A. (2013). A preservice teacher's delivery of sport education: Influences, difficulties and continued use. Journal of Teaching in Physical Education, 32(2), 166-185.

Hannum, W. (2005). Instructional systems development: A 30 year retrospective. Educational Technology, 45(4), 521.

McMahon, E., \& MacPhail, A. (2007). Learning to teach sport education: The experiences of a pre-service teacher. European Physical Education Review, 13, 229-249.

Siedentop, D., Hastie, P., \& van der Mars, H. (2020). Complete guide to sport education (3rd ed.). Champaign, IL: Human Kinetics.

\section{Journal of Health Sports \& Kinesiology | ISSN 2692-9864 | www.johsk.com}

